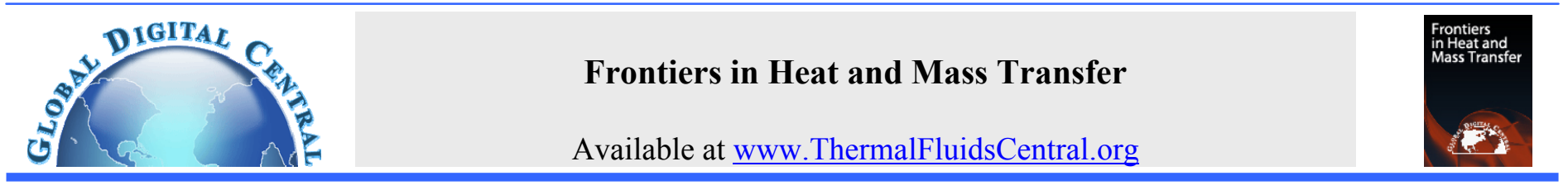

\title{
ONSET OF NUCLEATE BOILING IN MINI AND MICROCHANNELS: A BRIEF REVIEW
}

\author{
Tomio Okawa ${ }^{*}, \dagger$ \\ Department of Mechanical Engineering, Osaka University, Suita-shi, Osaka 565-0871, Japan
}

\begin{abstract}
The present article summarizes the studies on the thermalhydraulic condition under which the onset of nucleate boiling (ONB) is triggered in subcooled flow boiling. Available correlations and experimental data show that the ONB is tended to be delayed in mini and microchannels. It is known that the ONB condition is significantly dependent on the surface condition even in conventional-sized channels. Accumulation of ONB data accompanied by the information on the surface condition is therefore considered of importance to elucidate the mechanisms of boiling incipience in microchannels. Discussion is also made for the bubble dynamics observed in mini and microchannels. It is indicated that the bubble behavior at ONB in mini and microchannels may significantly be different from that in conventional-sized channels and have greater impact on the system performance. Further studies on the bubble dynamics following nucleation at ONB are also requested to improve the design of heat transfer devices using mini and microchannels.
\end{abstract}

Keywords: Microchannel, Subcooled flow boiling, Onset of nucleate boiling, Bubble dynamics.

\section{INTRODUCTION}

The use of small diameter channels is a promising way to increase the heat transfer area per unit volume in heat exchangers. Furthermore, the coolant flow rate required for dissipating a given amount of heat can be reduced if the latent heat transfer is employed. Flow boiling in mini and microchannels is hence expected to be a promising way to achieve effective heat dissipation particularly from small areas (Kandlikar, 2006), and has received increasing attention mainly due to extremely high power density encountered in recent miniaturized electronic devices (Mudawar, 2001; Thome, 2004). Although there exist several important parameters in flow boiling including the heat transfer coefficient and critical heat flux (Thome, 2004; Bergles and Kandlikar, 2005; Roday and Jensen, 2009), the present article focuses on the onset of nucleate boiling (ONB) in mini and microchannels.

In subcooled flow boiling in conventional-sized channels, the vapor void fraction near the location of ONB can be positive only in the region close to the heated wall. In consequence, the void fraction just downstream of the point of ONB is small, and a rapid increase in the void fraction or the onset of significant void (OSV) occurs further downstream of the ONB point (Collier and Thome, 1994); the void fraction between the locations of ONB and OSV is hence usually neglected. However, since the location of ONB corresponds to the boundary between the single- and two-phase regions, pressure loss and heat transfer characteristics are different between upstream and downstream of the point of ONB. For instance, Basu et al. (2002) indicated that single-phase heat transfer prevails upstream of the ONB point, but the presence of bubbles permits various heat transfer mechanisms downstream of it. It is also reported that the bubble behavior at ONB can significantly be different depending on the experimental setup (Bibeau and Salcudean, 1994; Thorncroft et al.,
1998; Okawa et al., 2005; Ahmadi et al., 2012). In consequence, many correlations and models have been developed so far to predict the location of ONB in subcooled flow boiling; some of them are discussed in the following section.

In mini and microchannels, several investigators reported that the wall superheats needed for boiling incipience can noticeably be higher than those predicted by the conventional correlations (Hapke et al., 2000; Kennedy et al., 2000; Martín-Callizo et al., 2007; Qi et al., 2007). Since the presence of bubbles alters the characteristics of the pressure loss and heat transfer as in the conventional-sized channels, accurate prediction of ONB is of importance in the design of the heat exchangers or the heat sinks using microchannels. Furthermore, once the ONB occurs in microchannels, a bubble can grow rapidly and most of the channel cross-section may be occupied by bubbles (Kandlikar and Balasubramanian, 2004; Hetsroni et al., 2005a; Barber et al., 2010). This phenomenon may cause the onset of flow instability leading to a decreased CHF value and significant oscillations of system pressure and heat transfer rate (Hetsroni et al., 2005a; Bergles and Kandlikar, 2005; Kuo and Peles, 2008). Absence of apparent partial boiling prior to fullydeveloped nucleate boiling (Peng and Wang, 1993) and a considerable wall temperature drop at ONB (Piasecka et al., 2004; Qi et al., 2007) were also reported. It is considered that the ONB may have greater impact on the system performance in the heat transfer devices using mini and microchannels.

The main purpose of the present brief review is to summarize available studies regarding the thermalhydraulic conditions under which nucleate boiling commences in forced-convective subcooled flow boiling. Since the bubble behavior in mini and microchannels can significantly be different from that observed in conventional-sized channels, studies concerning the bubble dynamics at ONB are also addressed.

\footnotetext{
* Currently in Department of Mechanical Engineering and Intelligent Systems, The University of Electro-Communications, Chofu-shi, Tokyo 182-8585, Japan

† Corresponding author.Email: okawa.tomio@uec.ac.jp
} 


\section{ONB CORRELATIONS FOR GENERAL PURPOSES}

The necessary condition for the boiling incipience postulated by Hsu (1962) has been used as the basis in many subsequent correlations for ONB. Considering a tiny bubble nucleus sitting at the mouse of a cavity as illustrated in Fig. 1, Hsu hypothesized that the bubble nucleus does not grow if the minimum temperature of the surrounding liquid is lower than the bubble temperature. It was assumed that the size of bubble nucleus $r_{b}$ is proportional to the cavity mouth radius $r_{c}$ and also dependent on the contact angle $\theta$. Since the bubble temperature $T_{b}$ is assumed to be equal to the saturation temperature corresponding to the pressure inside the nucleus, a decreased value of $r_{c}$ or $r_{b}$ leads to an increase in $T_{b}$ from the Young-Laplace equation $\left(P_{b}-P_{l}=2 \sigma / r_{b}\right)$ and the Clasius-Clapeyron equation $\left(d P / d T=\Delta h_{V} \rho_{v} / T_{S A T}\right)$. On the other hand, the minimum liquid temperature at the tip of the bubble nucleus decreases with an increase in $r_{c}$ due to sharp temperature gradient formed near the heated wall. In consequence, Hsu derived a quadratic equation to show that given the wall superheat $\Delta T_{W}$ and the liquid subcooling $\Delta T_{S U B}$, the cavities within the following size range may be activated.

$$
\left\{r_{c, \text { min }}, r_{c, \text { max }}\right\}=A\left[1 \mp \sqrt{1-\frac{8 \sigma T_{S A T}(1+\cos \theta)\left(\Delta T_{W}+\Delta T_{S U B}\right)}{\Delta h_{V} \rho_{v} \delta \Delta T_{W}^{2}}}\right]
$$

where $\delta$ denotes the thickness of the thermal layer in which the liquid temperature is higher than the bulk temperature, and $A$ is given by

$$
A=\frac{\delta \sin \theta \Delta T_{W}}{2(1+\cos \theta)\left(\Delta T_{W}+\Delta T_{S U B}\right)}
$$

Since no cavity can be activated if the discriminant of the quadratic equation is negative, the necessary condition for ONB is given by

$$
\frac{8 \sigma T_{S A T}(1+\cos \theta)\left(\Delta T_{W}+\Delta T_{S U B}\right)}{\Delta h_{V} \rho_{v} \delta \Delta T_{W}^{2}}=1
$$

Hsu noted that the ONB condition can deviate from Eq. 2 if the size range of the cavities on the heated surface is narrow, but claimed that Eq. 2 is still useful since the presence of cavities of a wide spectrum in sizes can be expected for most commercially available surfaces. For the value of $\theta$, Hsu assumed that $\theta=53^{\circ}(\cos \theta=0.6)$ for simplicity. Figure 1 however indicates that the distance of the bubble tip from the wall $y_{b}$ increases with a decrease in $\theta$. Reflecting this fact, Eq. 2 derived by Hsu suggests that the onset of nucleate boiling is delayed if the surface wettability is improved.

Sato and Matsumura (1963) developed a similar model independently of Hsu. They assumed a hemispherical bubble nucleus $(\theta$ $=90^{\circ}$ ) and linked the thermal layer thickness $\delta$ in Eq. 2 with the heat flux $q_{W}$. Assuming a linear temperature profile near the heated surface $\left(T_{l}=T_{W}-\left(q_{W} / k_{l}\right) y\right)$, Eq. 2 is transformed to

$q_{W}=\frac{\Delta h_{V} \rho_{v} k_{l} \Delta T_{W}^{2}}{8 \sigma T_{S A T}}$

Since the above equation defines the relation of $q_{W}$ and $\Delta T_{W}$ at ONB, the ONB condition can be determined if it is combined with a heat transfer equation for single-phase flow, $q_{W}=h_{S P}\left(\Delta T_{W}+\Delta T_{S U B}\right)$. Using the Dittus-Böelter correlation for the heat transfer coefficient $h_{S P}$, Sato and Matsumura compared the predictions by Eq. 3 with experimental data. The ranges of channel diameter and pressure were 5.8 to $12 \mathrm{~mm}$ and 0.1 to $14 \mathrm{MPa}$, respectively, and reasonably good agreements were reported. In this model, the critical cavity radius $r_{c, \text { crit }}$ at which the first bubble is formed is calculated as

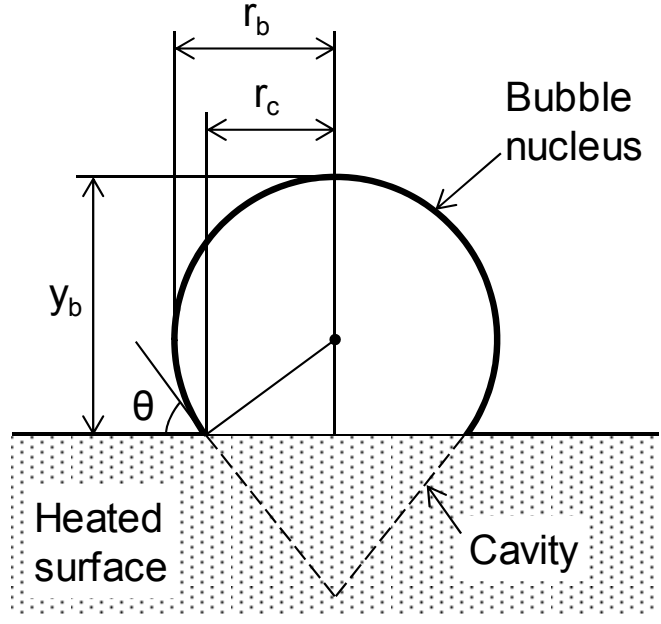

Fig. 1 Bubble nucleus sitting at the mouse of a cavity postulated by Hsu (1962).

$r_{c, c r i t}=\sqrt{\frac{2 k_{l} \sigma T_{S A T}}{\Delta h_{V} \rho_{v} q_{W}}}$

If the properties of saturated water under the atmospheric pressure and $q_{W}=0.2 \mathrm{MW} / \mathrm{m}^{2}$ are substituted to the above equation as a trial, $r_{c, \text { crit }}$ is calculated to be about $10 \mu \mathrm{m}$.

Davis and Anderson (1966) integrated the Clasius-Clapeyron equation strictly to derive a more precise expression for the ONB condition. If the pressure increment in a bubble nucleus is not significant, their expression reduces to

$q_{W}=\frac{\Delta h_{V} \rho_{v} k_{l} \Delta T_{W}^{2}}{8 \sigma T_{S A T}(1+\cos \theta)}$

This equation is identical to Eq. 3 if $\theta$ is set to $90^{\circ}$. They also investigated the ONB condition when only small cavities are available on a heated surface. If the maximum cavity size $r_{c, \max }$ is smaller than $r_{c, \text { crit }}$, the approximate expression for the ONB condition is given by

$q_{W}=\frac{k_{l} \sin \theta}{r_{c, \max }(1+\cos \theta)}\left[\Delta T_{W}-\frac{2 \sigma T_{S A T} \sin \theta}{\Delta h_{V} \rho_{v} r_{c, \max }}\right]$

They showed that, for the data of flow boiling of benzene and water in a copper tube of smooth surface, Eq. 5 considerably underestimates the wall superheats at the boiling incipience in a liquid film but fairly good agreements are achieved if $r_{c, \max }$ is set to $1 \mu \mathrm{m}$ in Eq. 6 (the use of a complete version of Eq. 6 is recommended for water data in the original paper). The value of $1 \mu \mathrm{m}$ was consistent with the observation result of the copper surface using a microscope. They concluded that specific information on the cavity size is needed to predict the ONB condition if a cavity size range available on the heated surface is limited.

Although a linear temperature profile within the thermal layer is postulated in the models mentioned above, it is obvious that the temperature field is affected by the presence of a bubble nucleus. Kandlikar et al. (1997) and Kandlikar (2006) further included the effect of bubble nucleus on the thermalhydraulic field around it by means of numerical simulation. It was shown that the ONB condition is expressed by the following equation if there is no lack of cavities of various sizes: 
$q_{W}=\frac{\Delta h_{V} \rho_{\mathrm{v}} k_{l} \Delta T_{W}^{2}}{8.8 \sigma T_{S A T}}$

If the most preferable cavity of $r_{c}=r_{c r i t}$ is not available on the surface, the ONB condition is given by

$q_{W}=\frac{k_{l} \sin \theta_{r}}{1.1 r_{c, \text { max }}}\left[\Delta T_{W}-\frac{2 \sigma T_{S A T} \sin \theta_{r}}{\Delta h_{V} \rho_{v} r_{c, \text { max }}}\right]$

where $\theta_{r}$ is the receding contact angle.

Even if a cavity is available on a heated surface, it does not work as an active nucleation site unless it can entrap noncondensable gas or vapor in it (Collier and Thome, 1994). Since the condition of entrapment is dependent on the surface wettability as discussed by Yang and Kim (1988), the contact angle would be influential not only in the shape of bubble nucleus sitting on a cavity mouse but also in the size distribution of unflooded cavities. In view of this, Basu et al. (2002) introduced a correction factor $F$ to the ONB criterion as

$q_{W}=\frac{F^{2} \Delta h_{V} \rho_{v} k_{l} \Delta T_{W}^{2}}{2 \sigma T_{S A T}}$

where $F$ is the function of $\theta$ and determined from available experimental data as

$F=1-\exp \left[-\left(\frac{\pi \theta}{180}\right)^{3}-0.5\left(\frac{\pi \theta}{180}\right)\right]$

The validity of this correlation was tested against the experimental data for various combinations of fluids and surface materials; the resulting range of $\theta$ was 1 to $85^{\circ}$.

Because of complexity of the phenomenon and industrial importance, empirical correlations for water have also been developed of which the notable ones are shown below:

$q_{W}=0.00180 P^{1.156}\left(1.8 \Delta T_{W}\right)^{2.83 / P^{0.0234}}$

$q_{W}=1949 \Delta T_{W}^{2} \exp \left(2.26 \times 10^{-7} P\right)$

The original expressions were rewritten in the SI units in the above equations. Equation 11 by Bergles and Rohsenow (1964) was derived based on water data over a wide pressure range of 0.1 to $13.8 \mathrm{MPa}$. Celata et al. (1997) showed that Eq. 12 by Thom et al. (1965) provides good agreements with water subcooled flow boiling data obtained under high mass flux and high liquid subcooling conditions.

As an example, the ONB criterions for water subcooled flow boiling calculated by the correlations shown above are compared under the condition of $D=10 \mathrm{~mm}, P=0.1 \mathrm{MPa}, G=1000 \mathrm{~kg} / \mathrm{m}^{2} \mathrm{~s}, \Delta T_{S U B}=20 \mathrm{~K}$, $\theta=\theta_{r}=45^{\circ}$ and $r_{c, \max }=1 \mu \mathrm{m}$ in Fig. 2 . The black curve in the figure indicates the heat transfer equation for single-phase flow simply calculated using the following widely-used correlation for the heat transfer coefficient.

$N u=0.023 \operatorname{Re}^{0.8} \operatorname{Pr}^{0.4}$

where $N u, R e$ and $P r$ are the Nusselt, Reynolds, and Prandtl numbers, respectively. The intersection of each correlation with the heat transfer equation is commonly assumed to correspond to the ONB condition. It can be seen that the calculated results by Eqs. 6 and 8 are considerably different from those by other correlations. This indicates the possibility that $\Delta T_{W}$ and $q_{W}$ at ONB can take significantly higher values if a cavity size range on the heated surface is limited. In order to investigate the effect of surface wettability, the value of $\theta$ was changed parametrically in Eq. 5 by Davis and Anderson (1966) and Eq. 9 by Basu et al. (2002). The results are delineated in Fig. 3. It can be seen that the effect of $\theta$ is rather insignificant in Eq. 5 but slight decrease in $\theta$ leads to a significant increase in the values of $\Delta T_{W}$ and $q_{W}$ at ONB in Eq. 9 particularly when $\theta$ is small, suggesting that considerable portion of cavities cannot be activated due to flooding in the case of hydrophilic heated surfaces.

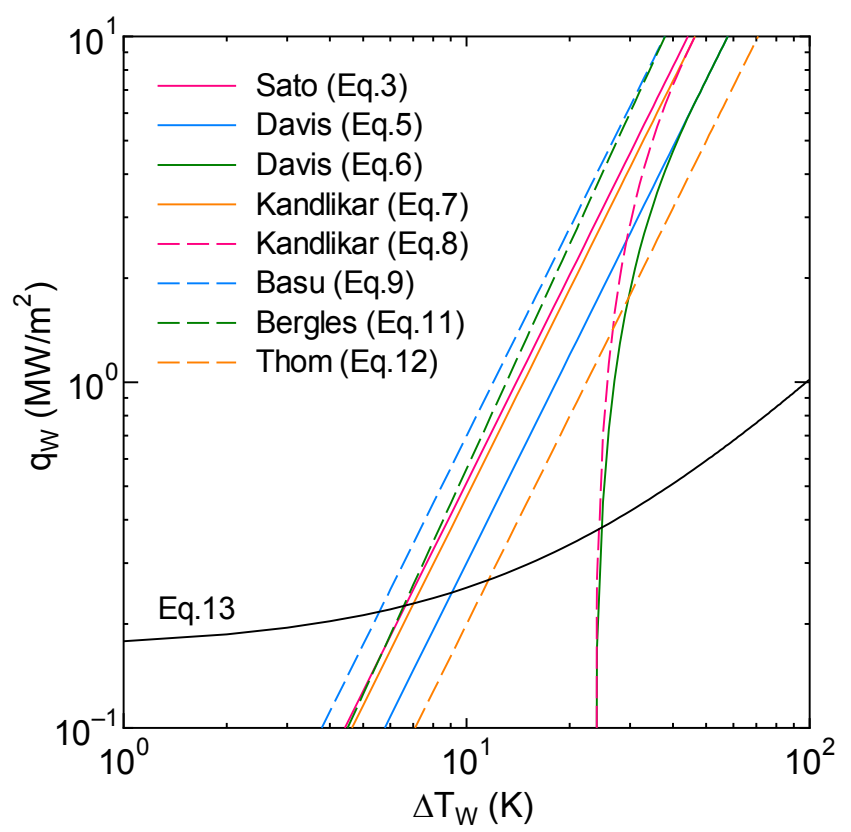

Fig. 2 Comparison of the existing ONB correlations for general purposes under the condition of $D=10 \mathrm{~mm}, P=0.1 \mathrm{MPa}, G=$ $1000 \mathrm{~kg} / \mathrm{m}^{2} \mathrm{~s}, \Delta T_{S U B}=20 \mathrm{~K}, \theta=\theta_{r}=45^{\circ}$ and $r_{c, \max }=1 \mu \mathrm{m}$.

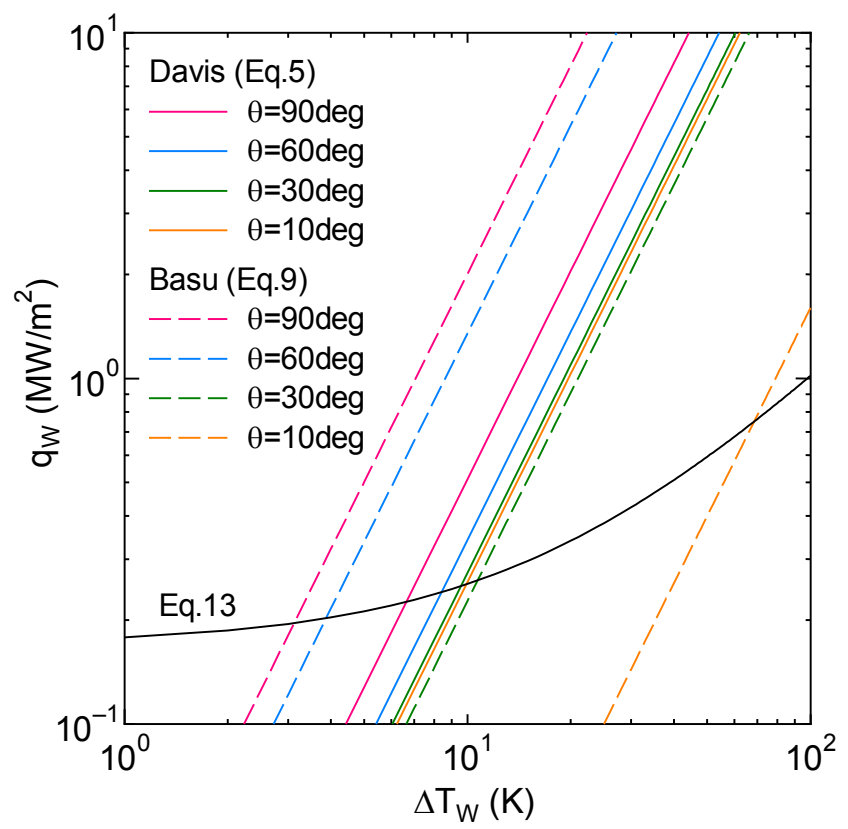

Fig. 3 Dependence of the ONB condition on the contact angle $\theta$ estimated by the correlations developed by Davis and Anderson (Eq. 5) and Basu et al. (Eq. 9). 


\section{STUDIES ON THE ONSET OF NUCLEATE BOILING IN MINI AND MICROCHANNELS}

\subsection{Models and Correlations}

Several investigators proposed the correlations for the ONB condition in mini and microchannels. Ghiaasiaan and Chedester (2002) found that the correlations by Bergles and Rohsenow (1964) and Sato and Matsumura (1963) tend to underestimate the ONB heat flux reported for water subcooled flow boiling in small-diameter tubes of $D=1$ to $1.45 \mathrm{~mm}$ (Inasaka et al., 1989; Kennedy et al., 2000). Ghiaasiaan and Chedester (2002) then considered that the liquid temperature at the tip of the bubble nucleus should be higher than the bubble temperature for the nucleus to grow as supposed by Hsu (1962), but hypothesized that the suppressing effect of the thermocapillary (Marangoni) force acting on the bubble nucleus should further be balanced by the aerodynamic force on it. To include this additional effect, they introduced an empirical coefficient $C$ to Eq. 3 as

$q_{W}=\frac{\Delta h_{V} \rho_{v} k_{l} \Delta T_{W}^{2}}{8 C \sigma T_{S A T}}$

and assumed that $C$ is the function of the following dimensionless parameter $\xi$ representing the ratio of the thermocapillary force to the aerodynamic force.

$\xi=\frac{\sigma_{S A T}-\sigma_{W}}{\rho_{l} U^{2} r_{c, c r i t}}$

where $\sigma_{S A T}$ and $\sigma_{W}$ denote the values of the surface tension coefficient at $T_{S A T}$ and $T_{W}$, respectively, and $r_{c, c r i t}$ is calculated by Eq. 4 . The functional form of $C$ was determined empirically using the ONB data reported by Inasaka et al. (1989) and Kennedy et al. (2000) as

$$
C=\max \left(1,22 \xi^{0.765}\right)
$$

It can be seen that for small values of $\xi$, the value of $C$ is 1 and Eq. 14 reduces to Eq. 3 by Sato and Matsumura. On the other hand, the calculated values of $\xi$ were within 0.01 to 10 for the above databases, indicating that $C$ can take very high values in some experimental conditions. Based on the results of numerical simulation, Zhuan and Wang (2010) also discussed the importance of the Marangoni heat transfer at the onset of nucleate boiling in microchannels.

$\mathrm{Qu}$ and Mudawar (2002) observed that even at incipient boiling, bubbles grew to detachment size before departing into the liquid flow in water subcooled flow boiling in a rectangular microchannel. Then, they considered that the classical ONB criterion may not be adequate for describing the incipience conditions in microchannels, and took a different approach to predict the incipient boiling heat flux. Since the bubbles departed into the liquid flow even at ONB, they first calculated the bubble departure diameter from the balance of the forces acting on a bubble. The drag and surface tension forces were considered as the main components. Two-dimensional temperature field within the rectangular channel was then calculated and the heat flux at which the lowest temperature around the departing bubble just exceeded the saturation temperature was postulated to be the incipient boiling heat flux. Hence, their model has a resemblance to the bubble departure models that are usually used for the prediction of the net vapor generation in subcooled flow boiling in conventional-sized channels (Levy, 1965; Winterton, 1984). It was shown that the calculated incipient boiling heat fluxes were in good agreement with their experimental data for water subcooled flow boiling in a horizontal rectangular channel of $0.231 \mathrm{~mm}$ wide and $0.712 \mathrm{~mm}$ deep.

Liu et al. (2005) followed the treatment by Davis and Anderson (1966) but made a modification on the superheat equation to derive the following expression for the ONB condition:
$q_{W}=\frac{\Delta h_{V} \rho_{v} k_{l}}{2 \sigma(1+\cos \theta)}\left[T_{W}+T_{S A T}-2 \sqrt{T_{W} T_{S A T}}\right]$

Comparisons were made for the water data for the rectangular channel of $0.275 \mathrm{~mm}$ wide and $0.254 \mathrm{~mm}$ deep accumulated by themselves and those by $\mathrm{Qu}$ and Mudawar (2002). Although Eq. 17 tended to overestimate the incipient boiling heat flux slightly, the predictions agreed with the experimental data within $\pm 20 \%$.

Qi et al. (2007) performed the measurements of ONB condition for liquid nitrogen flowing in round tubes of 0.531 to $1.931 \mathrm{~mm}$ in diameter. They found that the correlations by Thom (Eq. 12) and Liu et al. (Eq. 17) underestimate the wall superheat and the heat flux at ONB measured in their experiments. It was however reported that the correlation by Thom correctly predicts the measured tendencies and a good agreement can be achieved if the model constant in Eq. 12 is adjusted as

$q_{W}=1064 \Delta T_{W}^{2} \exp \left(2.26 \times 10^{-7} P\right)$

The ONB correlations for mini and microchannels proposed by Liu et al. (Eq. 17) and Qi et al. (Eq. 18) are shown in Fig. 4. Here, $D$ is reduced to $1 \mathrm{~mm}$ but other conditions are the same as those used in Fig. 2; Eqs. 3, 5 and 6 are also displayed in the same figure for comparison. Since the Reynolds number is rather small $(R e \approx 3500)$, the heat transfer equation for fully-developed laminar flow $(N u=4.36)$ are also depicted. It can be confirmed that the correlation by Liu et al. is very close to Eq. 5 as also indicated by the authors. Although the correlation by Qi et al. predicts relatively higher values of $\Delta T_{W}$ and $q_{W}$, the values are still less than those calculated by Eq. 6 , in which the maximum cavity radius is assumed to be $1 \mu \mathrm{m}$.

Noted that although the heat transfer correlations widely accepted for single-phase flow in conventional-sized channels are displayed in Fig. 4, inadequacy of these correlations for the flow in microchannels has been indicated by many investigators (Ghiaasiaan and Chedester, 2002; Morini, 2004; Hetsroni et al., 2005b; Rosa et al., 2009). It should hence be noted that, in addition to the ONB correlation, development of reliable heat transfer correlation is needed for the accurate prediction of the boiling incipience in microchannels.

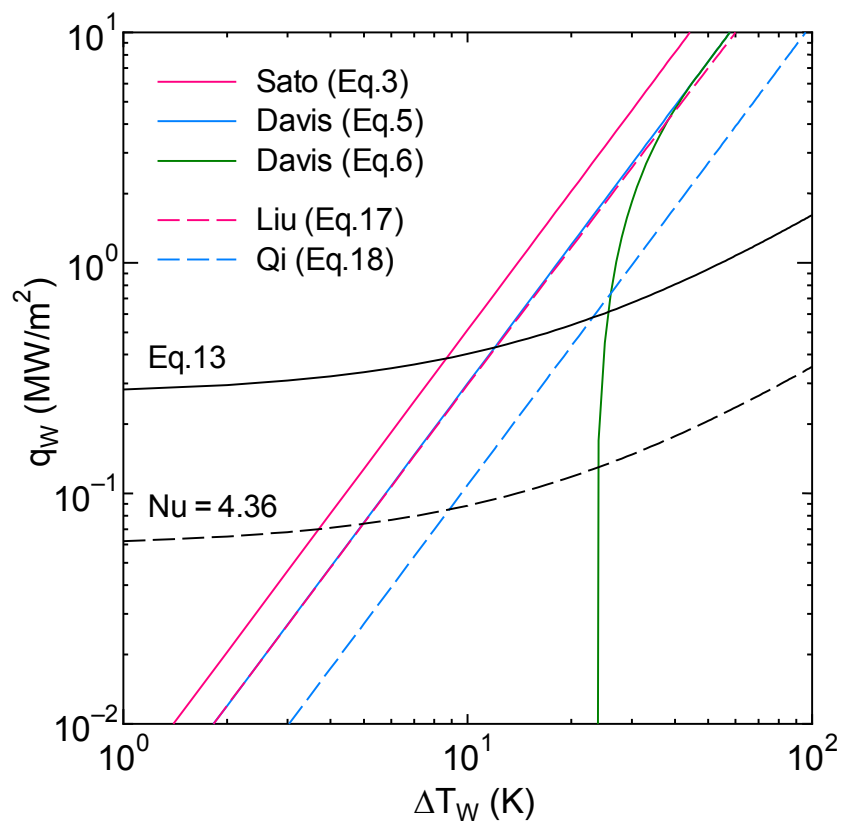

Fig. 4 Comparison of the ONB correlations for mini and microchannels $(D=1 \mathrm{~mm}$, other conditions are the same as those in Fig. 2). 
Table 1 Examples of ONB data in mini and microchannels available in literature.

\begin{tabular}{|c|c|c|c|c|c|}
\hline References & Fluid & $\begin{array}{c}\text { Material of } \\
\text { heated surface }\end{array}$ & Channel geometry & $\begin{array}{l}\text { Determination } \\
\text { method of } O N B\end{array}$ & Comments \\
\hline $\begin{array}{l}\text { Inasaka et al. } \\
\text { (1989) }\end{array}$ & Water & $\begin{array}{l}\text { Stainless steel } \\
304\end{array}$ & $\begin{array}{l}\text { Round tubes of } 1 \mathrm{~mm} \text { in } \\
\text { diameter }\end{array}$ & $\begin{array}{l}\text { Variation of } \\
\text { pressure loss }\end{array}$ & $\begin{array}{l}\text { - } q_{W} \text { at ONB agreed with the correlation } \\
\text { by Bergles and Rohsenow fairly well. }\end{array}$ \\
\hline $\begin{array}{l}\text { Hapke et al. } \\
(2000)\end{array}$ & Water & $\begin{array}{l}\text { Nickel base } \\
\text { alloy }\end{array}$ & $\begin{array}{l}\text { Round tube of } 1.5 \mathrm{~mm} \text { in } \\
\text { diameter }\end{array}$ & $\begin{array}{l}\text { Variation of } \\
\text { wall temperature }\end{array}$ & $\begin{array}{l}\text { - } \Delta T_{W} \text { at ONB was tended to be } \\
\text { underestimated by the correlations by } \\
\text { Sato and Matsumura and by Bergles } \\
\text { and Rohsenow particularly at high heat } \\
\text { fluxes. }\end{array}$ \\
\hline $\begin{array}{l}\text { Kennedy et al. } \\
(2000)\end{array}$ & Water & Copper & $\begin{array}{l}\text { Round tubes of } 1.17 \text { and } \\
1.45 \mathrm{~mm} \text { in diameter }\end{array}$ & $\begin{array}{l}\text { Variation of } \\
\text { pressure } \\
\text { gradient }\end{array}$ & $\begin{array}{l}\text { - } q_{W} \text { at ONB was underestimated by the } \\
\text { correlation by Bergles and Rohsenow. } \\
\text { - Experiments were conducted at } \\
\text { elevated pressures up to } 1 \mathrm{MPa} \text {. }\end{array}$ \\
\hline $\begin{array}{l}\text { Qu and } \\
\text { Mudawar } \\
(2002)\end{array}$ & Water & Copper & $\begin{array}{l}21 \text { parallel rectangular } \\
\text { channels of } 231 \mu \mathrm{m} \text { wide } \\
\text { and } 712 \mu \mathrm{m} \text { deep }\end{array}$ & $\begin{array}{l}\text { Visual } \\
\text { observation }\end{array}$ & $\begin{array}{l}\text { - A mechanistic model based on a bubble } \\
\text { departure criterion was developed. }\end{array}$ \\
\hline $\begin{array}{l}\text { Lee et al. } \\
(2004)\end{array}$ & Water & Silicon & $\begin{array}{l}\text { Single trapezoidal channel } \\
(103 \mu \mathrm{m} \text { in upper base, } 59 \\
\mu \mathrm{m} \text { in lower base and } 30 \mu \mathrm{m} \\
\text { in height })\end{array}$ & $\begin{array}{l}\text { Visual } \\
\text { observation }\end{array}$ & $\begin{array}{l}\text { - } \Delta T_{W} \text { and } q_{W} \text { at ONB agreed with Eq. } 6 \\
\text { if } r_{c, \max } \text { was set to } 1.5 \text { to } 4 \mu \mathrm{m} \text {. } \\
\text { - Information on the surface roughness } \\
\text { was reported. }\end{array}$ \\
\hline $\begin{array}{l}\text { Liu et al. } \\
(2005)\end{array}$ & Water & Copper & $\begin{array}{l}25 \text { parallel rectangular } \\
\text { channels of } 275 \mu \mathrm{m} \text { wide } \\
\text { and } 636 \mu \mathrm{m} \text { deep }\end{array}$ & $\begin{array}{l}\text { Visual } \\
\text { observation }\end{array}$ & $\begin{array}{l}\text { - } q_{W} \text { at ONB was slightly overestimated } \\
\text { by the correlation following the } \\
\text { treatment by Davis and Anderson. }\end{array}$ \\
\hline $\begin{array}{l}\text { Wu et al. } \\
(2006)\end{array}$ & Water & Silicon & $\begin{array}{l}8 \text { parallel trapezoidal } \\
\text { channels }(200 \mu \mathrm{m} \text { in upper } \\
\text { base, } 136 \mu \mathrm{m} \text { in lower base } \\
\text { and } 49 \mu \mathrm{m} \text { in height })\end{array}$ & $\begin{array}{l}\text { Visual } \\
\text { observation }\end{array}$ & $\begin{array}{l}\text { - Relation between ONB and OFI was } \\
\text { investigated. }\end{array}$ \\
\hline $\begin{array}{l}\text { Martín-Callizo } \\
\text { et al. (2007) }\end{array}$ & R-134a & $\begin{array}{l}\text { Stainless steel } \\
316\end{array}$ & $\begin{array}{l}\text { Round tubes of } 0.83,1.22 \\
\text { and } 1.70 \mathrm{~mm} \text { in diameter }\end{array}$ & $\begin{array}{l}\text { Variation of } \\
\text { wall temperature }\end{array}$ & $\begin{array}{l}\text { - } \Delta T_{W} \text { at ONB was underestimated by the } \\
\text { correlations by Sato and Matsumura } \\
\text { and by Bergles and Rohsenow. } \\
\text { - Significant temperature undershoot at } \\
\text { ONB was reported. }\end{array}$ \\
\hline Qi et al. (2007) & $\begin{array}{l}\text { Liquid } \\
\text { nitrogen }\end{array}$ & $\begin{array}{l}\text { Stainless steel } \\
304\end{array}$ & $\begin{array}{l}\text { Round tubes of } 0.531, \\
0.834,1.042 \text { and } 1.931 \mathrm{~mm} \\
\text { in diameter }\end{array}$ & $\begin{array}{l}\text { Variation of } \\
\text { wall temperature }\end{array}$ & $\begin{array}{l}\Delta T_{W} \text { and } q_{W} \text { at ONB were } \\
\text { underestimated by the correlations by } \\
\text { Liu et al. and Thom et al. }\end{array}$ \\
\hline $\begin{array}{l}\text { Kuo and Peles } \\
(2008)\end{array}$ & Water & Silicon & $\begin{array}{l}5 \text { parallel rectangular } \\
\text { channels of } 200 \mu \mathrm{m} \text { wide } \\
\text { and } 253 \mu \mathrm{m} \text { deep }\end{array}$ & $\begin{array}{l}\text { Variation of } \\
\text { wall temperature }\end{array}$ & $\begin{array}{l}\text { - } q_{W} \text { at ONB decreased for the surfaces } \\
\text { with artificial reentrant cavities. }\end{array}$ \\
\hline $\begin{array}{l}\text { Kuo and Peles } \\
(2009 a)\end{array}$ & HFE-7000 & Silicon & $\begin{array}{l}5 \text { parallel rectangular } \\
\text { channels of } 200 \mu \mathrm{m} \text { wide } \\
\text { and } 250 \mu \mathrm{m} \text { deep }\end{array}$ & $\begin{array}{l}\text { Visual } \\
\text { observation }\end{array}$ & $\begin{array}{l}\text { - } q_{W} \text { at ONB decreased for the surfaces } \\
\text { with artificial reentrant cavities. }\end{array}$ \\
\hline $\begin{array}{l}\text { Lee et al. } \\
(2011)\end{array}$ & Water & Silicon & $\begin{array}{l}\text { Single square or rectangular } \\
\text { channels }(100 \mu \mathrm{m} \text { wide and } \\
100 \mu \mathrm{m} \text { high; } 100 \mu \mathrm{m} \text { wide } \\
\text { and } 48 \mu \mathrm{m} \text { high })\end{array}$ & $\begin{array}{l}\text { Visual } \\
\text { observation }\end{array}$ & $\begin{array}{l}\text { - Single artificial cavities of cylindrical } \\
\text { shape with conical inlet were used for } \\
\text { nucleation. }\end{array}$ \\
\hline
\end{tabular}

\subsection{Experimental Works}

Listed in Table 1 are the examples of available experimental data of the ONB condition in mini and microchannels. Although the result of comparison is not always reported, $\Delta T_{W}$ and $q_{W}$ at ONB are usually higher than those predicted by conventional correlations (Hapke et al., 2000; Kennedy et al., 2000; Martín-Callizo et al., 2007; Qi et al., 2007) with a certain number of exceptions (Inasaka et al., 1989; Liu et al., 2005). Even if the nucleation site density is constant, the total number of nucleation sites should be smaller in a microchannel because of its small surface area. Furthermore, since sophisticated methods are frequently adopted in the fabrication process, the surface of microchannel tends to be very smooth. For example, in the case of the microheaters fabricated by Lin (1998) using MEMS (micro-electromechanical system), the root mean square surface roughness was measured to be $6.5 \mathrm{~nm}$. In this extreme case, bubbles might be generated by homogeneous nucleation rather than heterogeneous nucleation. The lack of large cavities is hence considered to be one of 
the major reasons of the delay of ONB frequently encountered in microchannels. In fact, Lee et al. (2004) reported that Eq. 3 underestimated their experimental data of the incipient boiling heat flux in a trapezoidal microchannel, but reasonably good agreement was achieved if $r_{c, \max }$ was set to 1.5 to $4 \mu \mathrm{m}$ in Eq. 6 . These values were consistent with the maximum roughness of the heated surface measured using an atomic force microscope. Lee et al. (2011) also reported that the nucleation incipient conditions at single artificial cavities in their square and rectangular microchannels were well matched with the classical theory presented in section 2 of this article. Kuo and Peles (2008; 2009a) reported that the incipient boiling heat fluxes measured for the heated surfaces with artificial reentrant cavities were generally lower than those for a plane surface. This observation would also be the evidence that the ONB condition in microchannels is particularly sensitive to the surface condition.

Effect of the surface wettability should also be taken into consideration since cavities may be flooded due to the combinations of fluid and surface material of low contact angles. Although the effect of contact angle on the boiling incipience are discussed by several researchers (Basu et al, 2002; Qu and Mudawar, 2002; Li and Cheng, 2004), the ONB data in microchannels are usually not accompanied by the information regarding the surface wettability. In the case of microchannels, specific information on the surface properties is considered to be of particular importance to predict the ONB condition since the presence of cavities of a wide spectrum in sizes may not be expected.

An additional concern in predicting the ONB condition in microchannels would be the effect of channel geometry. Since a wide variety of cross-sectional shapes are adopted in microchannels as shown in Table 1, the heat flux, wall superheat and liquid velocity may vary in the circumferential direction $(\mathrm{Qu}$ and Mudawar, 2002; $\mathrm{Li}$ and Cheng, 2004). Sufficient attention should also be paid for the effect of the cross-sectional shape of the flow channel.

\subsection{Bubble Dynamics at ONB}

Lee et al. (2004) measured the bubble dynamics in a trapezoidal microchannel of $103 \mu \mathrm{m}$ in upper base, $59 \mu \mathrm{m}$ in lower base and $30 \mu \mathrm{m}$ in height; the material of heated surface was silicon and the working fluid was deionized water. In their experiment, bubbles were generated at the side walls, and grew at the nucleation site before sliding along the heated surface. The measured bubble departure diameters were within 19 to $47 \mu \mathrm{m}$ and correlated by the modified Levy's model (1967) fairly well, suggesting that the bubble departure was governed by the balance of drag and surface tension forces acting on a bubble. Fu et al (2010) observed the bubble behavior in the flow boiling of liquid nitrogen in a vertical quartz glass tube of 1.3 to $1.5 \mathrm{~mm}$ in diameter. They also observed that bubbles first grew at the nucleation sites and then slid along the wall. Since the size of the sliding bubbles immediately became comparable with the tube size, bubble detachment from the heated surface was usually not observed. Alternatively, they observed slug bubbles. It was reported that the bubble diameter first increased almost linearly with time, but the growth rate of the bubble in the axial direction had abrupt jump when the bubble size became comparable to the tube diameter.

Kandlikar (2006) made a discussion concerning the rapid growth of a bubble following nucleation in microchannels. The heat transfer equation for single-phase flow is expressed by

$q_{W}=h_{S P}\left(\Delta T_{W}+\Delta T_{S U B}\right)$

He showed that in microchannels, the liquid subcooling $\Delta T_{S U B}$ at ONB tends to be small because of the high heat transfer coefficient and can become negative (superheated) in some cases. This trend is intensified when the cavities of preferable sizes are not available on the heated surface since the value of $\Delta T_{W}$ can be high. Once nucleation is triggered in this low subcooling or superheated environment, the bubble may experience a rapid growth as observed by Hetsroni et al. (2005a) and Kandlikar (2006). Lee et al. (2011) also observed that the bubble behavior after nucleation was significantly dependent on the wall superheat at ONB and the bubble grew in an explosive manner when the superheat was higher. This phenomenon is of importance in the design of microchannel heat sinks. For example, Steinke and Kandlikar (2004) expected that the rapid bubble growth was the main cause of anomalous heat transfer coefficients measured at low vapor qualities in their experiment using 6 parallel microchannels of 0.214 $\mathrm{mm}$ wide and $0.2 \mathrm{~mm}$ deep. Since rapidly growing bubble may occupy most of the channel cross-section in microchannels, the rapid bubble growth can induce a pressure spike to cause transient flow reversal toward the inlet of the microchannel (Kandlikar, 2006; Kuo and Peles, 2008). Barber et al. (2010) investigated the relation between the pressure fluctuation and the bubble growth process in detail using FC72 as the working fluid. It was shown that the periodic pressure fluctuations could be explained in terms of the bubble dynamics. It is therefore considered that the ONB likely to lead to the onset of flow instability (OFI) in microchannels. In fact, Wu et al. (2006) reported that the conditions of ONB and OFI were much closer in the microchannels and the two conditions almost coincided at high heat fluxes. Several methods were therefore proposed to reduce the wall superheat at ONB and to mitigate the flow instability (Kandlikar, 2006; Kuo and Peles, 2008, 2009b; Liu et al., 2010).

\section{CONCLUSIONS}

Available studies concerning the onset of nucleate boiling (ONB) in subcooled flow boiling were briefly reviewed. The ONB correlations developed for general purposes indicate that the thermalhydraulic conditions at ONB are significantly dependent on the surface properties such as the size distribution of cavies and the contact angle. The delay of ONB frequently observed in mini and microchannels would partly be attributed to a relatively small number of cavities available on a heated surface. There might however be additional factors that influence the ONB condition in microchannels. It is considered that further accumulation of the ONB data accompanied by the information on the surface properties is of particular importance to elucidate the mechanisms of boiling incipience in mini and microchannels.

Because of the small channel size and the possible high wall superheat, bubbles formed at ONB may occupy most of the channel cross-section and experience unexpectedly high growth rate in microchannels. In consequence, bubble dynamics at ONB may have significant impact on the whole system. Understanding of the bubble behavior following nucleation and the development of the efficient method to mitigate the delay of ONB are also of importance to improve the system performance of the heat transfer devices using mini and microchannels.

\section{NOMENCLATURE}

$\begin{array}{ll}D & \text { channel diameter }(\mathrm{m}) \\ G & \text { mass flux }\left(\mathrm{kg} / \mathrm{m}^{2} \cdot \mathrm{s}\right) \\ h & \text { heat transfer coefficient }\left(\mathrm{W} / \mathrm{m}^{2} \cdot \mathrm{K}\right) \\ k & \text { thermal conductivity }(\mathrm{W} / \mathrm{m} \cdot \mathrm{K}) \\ N u & \text { Nusselt number }(\text { dimensionless }) \\ P & \text { Pressure }\left(\mathrm{N} / \mathrm{m}^{2}\right) \\ P r & \text { Prandtl number }(\text { dimensionless }) \\ q_{W} & \text { heat flux }\left(\mathrm{W} / \mathrm{m}^{2}\right) \\ R e & \text { Reynolds number }(\text { dimensionless }) \\ r_{b} & \text { radius of bubble nucleus }(\mathrm{m}) \\ r_{c} & \text { radius of cavity mouth }(\mathrm{m}) \\ T & \text { temperature }(\mathrm{K}) \\ U & \text { mean velocity }(\mathrm{m} / \mathrm{s}) \\ y & \text { distance from the wall }(\mathrm{m})\end{array}$

Greek Symbols

$\Delta h_{V} \quad$ latent heat of vaporization $(\mathrm{J} / \mathrm{kg})$

$\Delta T_{W} \quad$ wall superheat $(\mathrm{K})$ 


$\begin{array}{ll}\Delta T_{S U B} & \text { liquid subcooling }(\mathrm{K}) \\ \delta & \text { thermal layer thickness }(\mathrm{m}) \\ \theta & \text { contact angle }(\text { degree }) \\ \rho & \text { density }\left(\mathrm{kg} / \mathrm{m}^{3}\right) \\ \sigma & \text { surface tension }(\mathrm{N} / \mathrm{m})\end{array}$

$\begin{array}{ll}\text { Subscripts } & \\ b & \text { bubble } \\ c r i t & \text { critical } \\ l & \text { liquid phase } \\ \max & \text { maximum } \\ \min & \text { minimum } \\ r & \text { receding } \\ S A T & \text { saturation } \\ S P & \text { single phase } \\ v & \text { vapor phase } \\ W & \text { wall }\end{array}$

\section{REFERENCES}

Ahmadi, R., Ueno, T., Okawa, T., 2012, "Bubble dynamics at boiling incipience in subcooled upward flow boiling," International Journal of Heat and Mass Transfer, 55(1-3), 488-497.

http://dx.doi.org/10.1016/j.ijheatmasstransfer.2011.09.050

Basu, N., Warrier, G.R., and Dhir, V.K., 2002, "Onset of nucleate boiling and active nucleation site density during subcooled flow boiling," Journal of Heat Transfer, 124(4), 717-728. http://dx.doi.org/10.1115/1.1471522

Barber, J., Brutin, D., Sefiane, K., and Tadrist, L., 2010, "Bubble confinement in flow boiling of FC-72 in a "rectangular" microchannel of high aspect ratio," Experimental Thermal and Fluid Science, 34(8), $1375-1388$.

http://dx.doi.org/10.1016/j.expthermflusci.2010.06.011

Bergles, A.E., and Kandlikar, S.G., 2005, "On the nature of critical heat flux in microchannels," Journal of Heat Transfer, 127(1), 101-107. http://dx.doi.org/10.1115/1.1839587

Bergles, A.E., and Rohsenow, W.M., 1964, "The determination of forced-convection surface-boiling heat transfer," Journal of Heat Transfer, 1, 365-372.

Bibeau, E.L., and Salcudean, M., 1994, "A study of bubble ebullition in forced-convective subcooled nucleate boiling at low pressure," International Journal of Heat and Mass Transfer, 37(15), 2245-2259.

Celata, G.P., Cumo, M., and Mariani, A., 1997, "Experimental evaluation of the onset of subcooled flow boiling at high liquid velocity and subcooling," International Journal of Heat Mass Transfer, 40(12), 2879-2885.

Collier, J.G., and Thome, J.R., 1994, Convective Boiling and Condensation, $3^{\text {rd }}$ ed., Oxford University Press, Oxford.

Davis, E.J., and Anderson, G.H., 1966, "The incipience of nucleate boiling in forced convection flow," AIChE Journal, 12(4), 774-780.

Fu, X., Zhang, P., Huang, C.J., and Wang, R.Z., 2010, "Bubble growth, departure and the following flow pattern evolution during flow boiling in a mini-tube," International Journal of Heat and Mass Transfer, 53(21-22), 4819-4831.

http://dx.doi.org/10.1016/j.ijheatmasstransfer.2010.06.010

Ghiaasiaan, S.M., and Chedester, R.C., 2002, "Boiling incipience in microchannels," International Journal of Heat and Mass Transfer, 45(23), 4599-4606.

http://dx.doi.org/10.1016/S0017-9310(02)00167-9
Hapke, I., Boye, H., and Schmidt, J., 2000, "Onset of nucleate boiling in minichannels," International Journal of Thermal Sciences, 39(4), 505-513.

Hetsroni, G., Mosyak, A., Pogrebnyak, E., and Segal, Z., 2005a, "Explosive boiling of water in parallel micro-channels," International Journal of Multiphase Flow, 31(4), 371-392. http://dx.doi.org/10.1016/j.ijmultiphaseflow.2005.01.003

Hetsroni, G., Mosyak, A., Pogrebnyak, E., Yarin, L.P., 2005b, Heat transfer in micro-channels: Comparison of experiments with theory and numerical results, International Journal of Heat and Mass Transfer, 48(25-26), 5580-5601.

http://dx.doi.org/10.1016/j.ijheatmasstransfer.2005.05.041

Hsu, Y.Y., 1962, "On the size range of active nucleation cavities on a heated surface," Journal of Heat Transfer, 84, 207-216.

Inasaka, F., Nariai, H., and Shimura, T., 1989, "Pressure drop in subcooled boiling in narrow tubes," Heat Transfer-Japanese Research, 18, 70-82.

Kandlikar, S.G., 2006, "Nucleation characteristics and stability considerations during flow boiling in microchannels," Experimental Thermal and Fluid Science, 30(5), 441-447. http://dx.doi.org/10.1016/i.expthermflusci.2005.10.001

Kandlikar, S.G., and Balasubramanian, P., 2004, "An experimental study on the effect of gravitational orientation on flow boiling of water in $1054 \times 197 \mu \mathrm{m}$ parallel minichannels," Journal of Heat Transfer, 127(8), 820-829.

http://dx.doi.org/10.1115/1.1928911

Kandlikar, S.G., Mizo, V., Cartwright, M., and Ikenze, E., 1997, "Bubble nucleation and growth characteristics in subcooled flow boiling of water," Proceedings of National Heat Transfer Conference, ASME, HTD-342, pp. 11-18.

Kennedy, J.E., Roach Jr., G.M., Dowling, M.F., Abdel-Khalik, S.I., Ghiaasiaan, S.M., Jeter, S.M., and Quershi, Z.H., 2000, "The onset of flow instability in uniformly heated horizontal microchannels," Journal of Heat Transfer, 122(1), 118-125. http://dx.doi.org/10.1115/1.521442

Kuo, C.-J., and Peles, Y., 2008, "Flow boiling instabilities in microchannels and means for mitigation by reentrant cavities," Journal of Heat Transfer, 130(7), art. no. 072402. http://dx.doi.org/10.1115/1.2908431

Kuo, C.-J., and Peles, Y., 2009a, "Flow boiling of coolant (HFE-7000) inside structured and plain wall microchannel," Journal of Heat Transfer, 131(12), 1-9.

http://dx.doi.org/10.1115/1.3220674

Kuo, C.-J., and Peles, Y., 2009b, "Pressure effects on flow boiling instabilities in parallel microchannels," International Journal of Heat and Mass Transfer, 52(1-2), 271-280.

http://dx.doi.org/10.1016/j.ijheatmasstransfer.2008.06.015

Lee, P.C., Tseng, F.G., and Pan, C., 2004, "Bubble dynamics in microchannels. Part I: Single microchannel," International Journal of Heat and Mass Transfer, 47(25), 5575-5589.

http://dx.doi.org/10.1016/j.ijheatmasstransfer.2004.02.031

Lee, J.Y., Kim, M.-H., Kaviany, M., Son, S.Y., 2011, "Bubble nucleation in microchannel flow boiling using single artificial cavity," International Journal of Heat and Mass Transfer, 54(25-26), 51395148.

http://dx.doi.org/10.1016/j.ijheatmasstransfer.2011.08.042

Levy, S., 1967, "Forced convection subcooled boiling-prediction of vapor volumetric faction," International Journal of Heat and Mass Transfer, 10, 951-965. 
Li, J., and Cheng, P., 2004, "Bubble cavitation in a microchannel," International Journal of Heat and Mass Transfer, 47, 2689-2698. http://dx.doi.org/10.1016/j.ijheatmasstransfer.2003.11.020

Lin, L., 1998, "Microscale thermal bubble formation, thermophysical phenomenon and applications," Microscale Thermophysics Engineering, 2, 71-85.

Liu, D., Lee, P.-S., and Garimella, S.V., 2005, "Prediction of the onset of nucleate boiling in microchannel flow," International Journal of Heat and Mass Transfer, 48(25-26), 5134-5149. http://dx.doi.org/10.1016/j.ijheatmasstransfer.2005.07.021

Liu, G., Xu, J., Yang, Y., 2010, "Seed bubbles trigger boiling heat transfer in silicon microchannels," Microfluidics and Nanofluidics, 8(3), 341-359.

http://dx.doi.org/10.1007/s10404-009-0465-y

Martín-Callizo, C., Palm, B., and Owhaib, W., 2007, "Subcooled flow boiling of R-134a in vertical channels of small diameter," International Journal of Multiphase Flow, 33(8), 822-832.

http://dx.doi.org/10.1016/j.ijmultiphaseflow.2007.02.002

Morini G.L., 2004, Single-phase convective heat transfer in microchannels: A review of experimental results, International Journal of Thermal Sciences, 43(7), 631-651. http://dx.doi.org/10.1016/j.ijthermalsci.2004.01.003

Mudawar, I., 2001, "Assessment of high-heat-flux thermal management schemes," IEEE Transactions on Components and Packaging Technologies, 24(2), 122-141.

http://dx.doi.org/10.1109/6144.926375

Okawa, T., Ishida, T., Kataoka, I., and Mori, M., 2005, "Bubble rise characteristics after the departure from a nucleation site in vertical upflow boiling of subcooled water," Nuclear Engineering and Design, 235(10-12), 1149-1161.

http://dx.doi.org/10.1016/j.nucengdes.2005.02.012

Peng, X.F., and Wang, B.-X., 1993, "Forced convection and flow boiling heat transfer for liquid flowing through microchannels," International Journal of Heat and Mass Transfer, 36(14), 3421-3427.

Piasecka, M., Hozejowska, S., and Poniewski, M.E., 2004, "Experimental evaluation of flow boiling incipience of subcooled fluid in a narrow channel," International Journal of Heat and Fluid Flow, 25(2), 159-172.

http://dx.doi.org/10.1016/i.ijheatfluidflow.2003.11.017

Qi, S.L., Zhang, P., Wang, R.Z., and Xu, L.X., 2007, "Flow boiling of liquid nitrogen in micro-tubes: Part I - The onset of nucleate boiling, two-phase flow instability and two-phase flow pressure drop," International Journal of Heat and Mass Transfer, 50(25-26), 49995016.

http://dx.doi.org/10.1016/j.ijheatmasstransfer.2007.08.018
Qu, W., and Mudawar, I., 2002, "Prediction and measurement of incipient boiling heat flux in micro-channel heat sinks," International Journal of Heat and Mass Transfer, 45(19), 3933-3945. http://dx.doi.org/10.1016/S0017-9310(02)00106-0

Roday, A.P., and Jensen, M.K., 2009, "A review of the critical heat flux condition in mini-and microchannels," Journal of Mechanical Science and Technology, 23(9), 2529-2547. http://dx.doi.org/10.1007/s12206-009-0711-y

Rosa, P., Karayiannis, T.G., Collins, M.W., 2009, Single-phase heat transfer in microchannels: The importance of scaling effects, Applied Thermal Engineering, 29(17-18), 3447-3468.

http://dx.doi.org/10.1016/j.applthermaleng.2009.05.015

Sato, T., and Matsumura, H., 1963, "On the conditions of incipient subcooled boiling with forced convection flow," Bulletin of JSME, 7(26), 392-398.

Steinke, M.E., and Kandlikar, S.G., 2004, "An experimental investigation of flow boiling characteristics of water in parallel microchannels," Journal of Heat Transfer, 126(4), 518-526. http://dx.doi.org/10.1115/1.1778187

Thom, J.R.S., Walker, W.M., Fallon, T.A., and Reising, G.F.S., 1965, "Boiling in subcooled water during flow up heated tubes or annuli," Proceedings of Symposium on Boiling Heat Transfer in Steam Generating Units and Heat Exchangers, Manchester, UK.

Thome, J.R., 2004, "Boiling in microchannels: A review of experiment and theory," International Journal of Heat and Fluid Flow, 25(2), 128139.

http://dx.doi.org/10.1016/j.ijheatfluidflow.2003.11.005

Thorncroft, G.E., Klausner, J.F., and Mei, R., 1998, “An experimental investigation of bubble growth and detachment in vertical upflow and downflow boiling," International Journal of Heat and Mass Transfer, 41(23), 3857-3871.

Winterton, R.H.S., 1984, "Flow boiling: prediction of bubble departure," International Journal of Heat and Mass Transfer, 27, 14221424 .

Wu, H.Y., Cheng, P., and Wang, H., 2006, "Pressure drop and flow boiling instabilities in silicon microchannel heat sinks," Journal of Micromechanics and Microengineering, 16(10), art. no. 030, 21382146.

http://dx.doi.org/10.1088/0960-1317/16/10/030

Yang, S.R., and Kim, R.H., 1988, "A mathematical model of the pool boiling nucleation site density in terms of the surface characteristics," International Journal of Heat and Mass Transfer, 31(6), 1127-1135.

Zhuan, R., and Wang, W., 2010, "Simulation on nucleate boiling in micro-channel," International Journal of Heat and Mass Transfer, 53(1-3), 502-512.

http://dx.doi.org/10.1016/j.ijheatmasstransfer.2009.08.019 